\title{
PERAN PERAWAT DALAM MENGANALISIS STANDAR SASARAN KESELAMATAN PASIEN DI RUMAH SAKIT
}

\author{
Muhaini Atmayana Purba / 181101131 \\ muhainipurba21@gmail.com
}

\begin{abstract}
ABSTRAK
Latar belakang : Keselamatan pasien adalah suatu sistem yang membuat asuhan pasien lebih aman, meliputi asesmen risiko, identifikasi dan pengelolaan risiko pasien, pelaporan dan analisis insiden, kemampuan belajar dari insiden serta tindak lanjutnya, juga implementasi membuat solusi untuk meminimalkan timbulnya risiko dan mencegah terjadinya cedera yang disebabkan oleh kesalahan akibat melaksanakan suatu tindakan. Tujuan : Tujuan penulisan ini yaitu mengidenifikasi peran perawat dalam menganalisis standar sasaran keselamatan pasien di rumah sakit. Metode : Metode yang digunakan merupakan literatur review atau suatu perbandingan atau analisis antara satu jurnal dengan jurnal lainnya dari berbagai sumber seperti referensi jurnal, buku teks dan e-book. Hasil : Menunjukkan bahwa pelaksanaan enam sasaran keselamatan pasien oleh perawat adalah baik sebesar 51,4\%. Adapun enam sasaran keselamatan pasien tersebut meliputi pelaksanaan ketepatan identifikasi pasien adalah baik sebesar 64,5\%, pelaksanaan komunikasi efektif adalah baik sebesar 56,1\%, peningkatan keamanan obat yang perlu adalah baik sebesar 50,5\%, kepastian tepat lokasi, prosedur dan pasien operasi adalah sebesar 59,8\%, pengurangan risiko infeksi adalah baik sebesar 50,5\%, dan pengurangan resiko jatuh adalah baik sebesar $61,7 \%$. Kesimpulan : Pelaksanaan enam sasaran keselamatan pasien oleh perawat dalam mencegah adverse event berada dalam kategori baik. Diharapkan instansi terkait melengkapi standar prosedur operasional mengenai komunikasi efektif saat melaporkan dan menerima instruksi dari dokter, pemberian tanda dan label untuk keamanan obat dan peningkatan supervisi agar pelaksanaan teknik aseptik menjadi lebih baik.
\end{abstract}

Kata Kunci : Peran perawat, sasaran keselamatan pasien, rumah sakit.

\begin{abstract}
Background : Patient safety is a system that makes patient care safer, including risk assessment, identification and management of patient risk, reporting and analysis of incidents, the ability to learn from incidents and their follow-up, as well as the implementation of making solutions to minimize risks and prevent injuries from occurring by mistakes resulting from carrying out an action. Purpose : The purpose of this paper is to identify the role of nurses in analyzing patient safety target standards in hospitals. Method : The method used is a literature review or a comparison or analysis of one journal with other journals from various sources such as journal references, textbooks and e-books. Results : Shows that the implementation of six patient safety goals by nurses is good at $51.4 \%$. The six patient safety targets include the implementation of the accuracy of patient identification is good at $64.5 \%$, the implementation of effective communication is good at $56.1 \%$, the improvement of the safety of drugs that need is good at $50.5 \%$, the certainty of the exact location, procedure and patient surgery was $59.8 \%$, reduction in risk of infection was good by $50.5 \%$, and reduction in risk of falling was good by $61.7 \%$. Conclusion : The implementation of six patient safety goals by nurses in preventing adverse events is in the good category. It is expected that the relevant agencies complete standard operational procedures regarding effective communication when reporting and receiving instructions from doctors, giving signs and labels to drug safety and improved supervision so that the implementation of aseptic techniques is better.
\end{abstract}

Keywords : Role of nurses, patient safety goals, hospitals. 


\section{Latar Belakang}

Rumah sakit dalam melaksanakan tujuan, fungsi dan perannya memerlukan suatu bentuk pengaturannya yang jelas. Banyak unsur-unsur yang terkandung di dalam penyelenggaraan Rumah Sakit terutama terkait dengan tugas utamanya dalam pelayanan publik yakni melakukan pelayanan kesehatan, maka membutuhkan perangkat hukum yang memadai. Hal itu dimaksudkan agar penyelenggaraannya sungguh-sungguh dapat sesuai dengan kedudukan, peran dan fungsinya, serta terutama untuk dapat memenuhi amanat konstitusi yaitu mewujudkan kesejahteraan masyarakat. Keselamatan didefinisikan sebagai kebebasan dari cedera psikologis dan fisik. Menurut World Health Organization (WHO), keselamatan pasien adalah tidak adanya bahaya yang mengancam kepada pasien selama proses pelayanan kesehatan. Berdasarkan Peraturan Menteri Kesehatan Nomor 11 Tahun 2017, keselamatan pasien merupakan suatu sistem yang membuat asuhan pasien lebih aman, meliputi asesmen risiko, identifikasi dan pengelolaan risiko pasien, pelaporan dan analisis insiden, kemampuan belajar dari insiden dan tindak lanjutnya, serta implementasi solusi untuk meminimalkan timbulnya risiko dan mencegah terjadinya cedera yang disebabkan oleh kesalahan akibat melaksanakan suatu tindakan atau tidak mengambil tindakan yang seharusnya diambil. Menurut National Health Performance Committee (NHPC, 2001,dikutip dari Australian Institute Health and Welfare (AIHW, 2009) mendefinisikan keselamatan pasien adalah menghindari atau mengurangi hingga ketingkat yang dapat diterima dari bahaya aktual atau risiko dari pelayanan kesehatan atau lingkungan dimana pelayanan kesehatan diberikan.

Keselamatan pasien menjadi isu terkini dalam pelayanan kesehatan rumah sakit sejak tahun 2000 yang didasarkan atas makin meningkatnya kejadian yang tidak diharapkan (KTD) atau adverse event. Adverse event merupakan suatu peristiwa yang dapat menyebabkan hal yang tak terduga atau tidak diinginkan sehingga membahayakan keselamatan pengguna alat kesehatan termasuk pasien atau orang lain. Klasifikasi adverse event adalah kejadian nyaris cedera (KNC), kejadian tidak cedera (KTC) dan sentinel (kematian atau cedera). Contoh dari KTD seperti medication error, flebitis, dekubitus, infeksi daerah operasi, dan pasien jatuh dengan cidera (Suhartono, 2013; Suryani et al., 2011).

Salah satu upaya untuk meminimalkan insiden atau kejadian patient safety, keperawatan sebagai pelayanan profesional yang merupakan ujung tombak pelayanan kepada pasien harus bertindak dengan didasari oleh ilmu pengetahuan termasuk pengetahuan tentang patient safety, sehingga asuhan keperawatan yang diberikan berkualitas dan bermanfaat dalam mencegah insiden kejadian tidak diharapkan atau KTD (Arumaningrum, 2014).

\section{Tujuan}

mengidenifikasi peran perawat dalam menganalisis standar sasaran keselamatan pasien di rumah sakit.

\section{Metode} Metode yang digunakan
merupakan literatur review atau suatu
perbandingan atau analisis antara satu 
jurnal dengan jurnal lainnya dari berbagai sumber seperti referensi jurnal, buku teks dan e-book.

\section{Hasil \& Pembahasan}

a. Kebijakan

RSUD Padang Pariaman telah membuat kebijakan dalam bentuk Surat Keputusan Direktur Nomor 445/101/RSUD_PD-PRM/XI/2016

tentang kebijakan sasaran keselamatan pasien. Kebijakan tersebut telah mengacu pada Permenkes dan KARS antara lain melakukan identifikasi pasien dengan benar, melakukan komunikasi yang efektif, meningkatkan keamanan pengelolaan obat yang perlu diwaspadai, memastikan tepat lokasi, tepat prosedur dan tepat pasien operasi, mengurangi resiko infeksi terkait pelayanan kesehatan dan mengurangi resiko pasien cedera karena jatuh.

Kebijakan yang telah dibuat oleh RSUD Padang Pariaman sudah disosialisasikan kepada seluruh staf sejak tahun 2017. Namun pelaksanaan sasaran keselamatan pasien belum optimal. Tim Keselamatan Pasien Rumah sakit (TKPRS) telah dibentuk pada tahun 2017 yang diketuai oleh Kepala Bidang Pelayanan Medis, dengan anggotanya yaitu tim pokja akreditasi.

\section{b. Pedoman/SPO}

Pedoman dan Standar Prosedur Operasiol (SPO) merupakan unsur terpenting dalam pelaksanaan suatu kegiatan. SPO berguna untuk menghemat usaha manajerial, memudahkan pendelegasian wewenang dan menempatkan tanggung jawab, menimbulkan pengembangan metodemetode operasional yang lebih efisien, memudahkan pengawasan, memungkinkan penghematan personalia dan membantu kegiatan koordinasi.

RSUD Padang Pariaman telah menyusun buku pedoman keselamatan pasien yang digunakan sebagai panduan dalam menerapkan sasaran keselamatan pasien. Dari hasil penelitian didapatkan bahwa buku pedoman dan SPO pelaksanaan sasaran keselamatan pasien di RSUD Padang Pariaman disusun sesuai dengan Permenkes dan KARS. Seluruh dokumen sudah tercukupi $100 \%$ khususnya di ruang rawat inap (Bedah dan Non Bedah). Tapi pelaksanaannya masih belum optimal, karena belum menjadi budaya bagi petugas pemberi pelayanan di RS.

c. Tenaga

Tenaga/Sumber Daya Manusia (SDM) merupakan asset penting dalam 
suatu organisasi dan motor penggerak proses manajemen. Tenaga dalam penelitian ini adalah petugas atau profesional yang terlibat langsung dalam pelaksanaan sasaran keselamatan pasien di rumah sakit. Fondasi yang digunakan dalam implementasi program keselamatan pasien adalah membangun kultur keselamatan pasien (culture of safety) dan disokong tiga pilar yaitu aspek teknologi, prosedur dan Sumber Daya Manusia (SDM).

Berdasarkan Permenkes nomor 56 tahun 2014 jumlah pegawai di RSUD Padang Pariaman sudah hampir mencukupi.14Upaya yang telah dilakukan ialah rekrutmen pegawai untuk memenuhi kebutuhan tenaga pelaksana di rumah sakit.

Tim keselamatan pasien belum pernah menyusun program kerja sehingga pembagian tugas baik ketua maupun anggota tim tidak jelas. Seyogyanya tim keselamatan pasien bertugas melaksanakan monitoring dan evaluasi program keselamatan pasien, pencatatan dan pelaporan insiden, analisis insiden termasuk melakukan RCA (Root Cause Analysis). $\quad$ Yang menjadi permasalahannya adalah belum ada penanggung jawab dari masing-masing kegiatan tersebut. d. Metode

Metode adalah suatu tatacara kerja yang bertujuan untuk memperlancar jalannya pelaksanaan sasaran keselamatan pasien. Hasil penelitian menunjukkan bahwa metode yang digunakan dalam pelaksanaan sasaran keselamatan pasien di rawat inap seperti pemasangan gelang untuk identifikasi pasien, komunikasi efektif dengan teknik SBAR masih belum optimal.

Meskipun SPO terkait keselamatan pasien di RSUD Padang Pariaman sudah mencukupi untuk kedua ruang rawat inap (Bedah dan Non Bedah), budaya menerapkan sasaran keselamatan pasien masih kurang. Petugas menganggap SPO hanya sebatas dokumen untuk memenuhi syarat akreditasi. Perlu adanya supervisi oleh tim keselamatan pasien dan pihak manajemen rumah sakit untuk membimbing dan memotivasi petugas serta untuk mengatasi masalah yang terjadi di rawat inap. Supervisi yang tidak adekuat, pelaksanaan tugas yang tidak sesuai rencana dan kegagalan untuk mengkoreksi masalah yang sudah teridentifikasi merupakan kondisi yang memudahkan anggota tim melakukan kesalahan dan pelanggaran. 
e. Dana

Berdasarkan hasil telusur
dokumen tentang dana untuk
pelaksanaan program keselamatan
pasien didapatkan data bahwa tidak ada

anggaran khusus untuk program keselamatan pasien. Anggaran tersebut melekat pada kegiatan bidang pelayanan dan bidang penunjang. Dalam hal ini, RSUD harus meningkatkan koordinasi antar bidang agar penggunaan dana dapat mendukung pelaksanaan program keselamatan pasien khususnya dalam proses pengadaan dan pemeliharaan.

Selain itu dari hasil telaah dokumen, dana untuk pelaksanaan monitoring dan evaluasi terkait program keselamatan pasien belum pernah dianggarkan oleh manajemen RSUD Padang Pariaman. Reward berupa pemberian jasa pelayanan kepada Tim Keselamatan Pasien Rumah Sakit (TKPRS) juga belum ada. Hal ini berdampak pada kurangnya motivasi tim dalam bekerja.

\section{f. Sarana}

Sarana penunjang lainnya. Hal ini disebabkan karena kendala dalam hal pengadaan barang. Upaya dari manajemen rumah sakit ialah membuat laporan permintaan kebutuhan per tahun dari instalasi terkait kebutuhan alat kesehatan, bahan medis habis pakai dan kebutuhan pelayanan lainnya. Hal ini sejalan dengan penelitian di Rumah Sakit Pupuk Kalimantan Timur yang menyatakan bahwa sarana dan fasilitas masih belum maksimal. Dari hasil observasinya terdapat tempat tidur pasien yang belum aman, brankar yang tidak aman dan gelang penanda risiko masih sering kosong.

Ketersediaan sarana dan prasarana merupakan hal yang sangat penting dalam mendukung pelaksanaan sasaran keselamatan pasien. Hasil penelitian menunjukkan bahwa sarana untuk kebutuhan program keselamatan pasien di rawat inap RSUD Padang Pariaman sebagian sudah dilengkapi, namun ada beberapa sarana yang kosong, belum sesuai dengan standar dan rusak. Meskipun anggaran yang ada sudah mulai mencukupi namun masih sering terjadi kekosongan sarana rutin seperti bahan medis habis pakai dan

\section{Penutup}

\section{Kesimpulan \& Saran}

Pelaksanaan enam sasaran keselamatan pasien oleh perawat di rumah sakit berada dalam kategori baik. Diharapkan Pihak rumah sakit dapat melengkapi standar prosedur operasional mengenai komunikasi 
efektif saat melaporkan dan menerima instruksi dari dokter, adanya tanda dan label untuk keamanan obat, dan peningkatan supervisi agar pelaksanaan teknik aseptik menjadi lebih baik.

\section{Daftar Pustaka}

Aprilia, Shelly. (2011). Faktor-faktor yang Mempengaruhi Perawat dalam Penerapan IPSG pada Akreditasi JCI di Instalasi Rawat Inap RS Swasta X Tahun 2011. Skripsi. Program Sarjana Keperawatan Kesehatan Masyarakat Departemen Biostatistik dan Kependudukan. Fakultas Kesehatan Masyarakat. Universitas Indonesia Jakarta

Astuti, Tri Puji. (2013). Analisis Penerapan Manajemen Paisen Safety dalam Rangka Peningkatan Mutu Pelayanan di RS PKU Muhammadiyah Surakarta Tahun 2013. Skripsi. Universitas Muhammadiyah Sukarta

Cahyono, J.B.S.B. (2008). Membangun

Budaya Keselamatan Pasien dalam Praktik Kedokteran.

Jogjakarta : Alfabeta.

Departemen Kesehatan RI. (2006). Panduan Nasional Keselamatan Pasien Rumah Sakit. Jakarta: Departemen Kesehatan RI.

Dewi,Mursidah. (2012). Pengaruh Pelatihan Timbang Terima Pasien Terhadap Penerapan Keselamatan Pasien Oleh Perawat Pelaksana Di RSUD Raden Mattaher Jambi.Jurnal Health \& Suport.5,(3):647:652.
Neri, Reno Afriza, dkk. (2018).

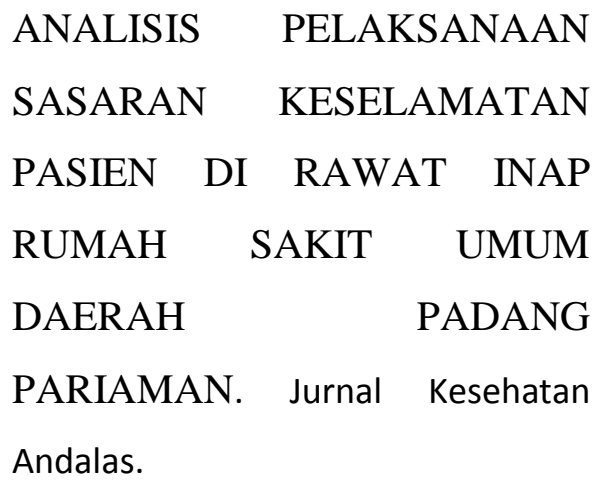

Notoatmodjo, S. (2003). Pendidikan dan Perilaku Kesehatan. Jakarta : PT. Rineka Cipta.

Notoatmodjo, S. (2007). Kesehatan Masyarakat Ilmu dan Seni. Jakarta : PT. Rineka Cipta

Nursery \& Champaca, Septi Machelia. (2016). PELAKSANAAN ENAM SASARAN KESELAMATAN PASIEN OLEH PERAWAT DALAM MENCEGAH ADVERSE EVENT DI RUMAH SAKIT. STIKES Suaka Insan Banjarmasin.

Potter \& Perry, (2005). Buku Ajar Fundamental Keperawatan : Konsep, Proses, dan Praktik. Edisi 4. Jakarta : EGC.

Rahayu, Sri. (2011). Pengembangan Program Patient Safety Berdasarkan Awareness dan Komitmen Individu. RSUD Ibnu Sina Kabupaten Gresik 
R.H, Simamora. (2019). Buku Ajar Pelaksanaan Identifikasi Pasien. Uwais Inspirasi Indonesia

R.H, Simamora. (2019). Documentation Of Patient Identification Into The Electronic System To Improve The Quality Of Nursing Services. International Jurnal Of Sciensific \& Technology

R.H, Simamora. (2019). The Influence Of Training Handover Based SBAR Communication For Improving Patients Safety. Indian Journal Of Public Health Research \& Deveropment.

Soeroso. S., 2003. Manajemen Sumber Daya Manusia Di Rumah Sakit Suatu Pendekatan Sistem. EGC, Jakarta.

Sunaryo, 2004. Psikologi Untuk Keperawatan. Penerbit Buku Kedokteran EGC, Jakarta.

Utami, Yuni Wulan \& Supratman. (2009). HUBUNGAN ANTARA PENGETAHUAN DENGAN SIKAP PERAWAT DALAM PEMENUHAN KEBUTUHAN SPIRITUAL PASIEN DI BRSUD SUKOHARJO. Berita Ilmu Keperawatan ISSN 1979-2697, Vol. 2 No. 2 : 69-74
Widajat, Rochmanadji. (2009). Being a Great and Sustainable Hospital. Jakarta : PT Gramedia Pustaka Utama

W. Keles, Angelia, dkk. (2015). Analisis Pelaksanaan Standar Sasaran Keselamatan Pasien di Unit Gawat Darurat RSUD Dr. Sam Ratulangi Tondano Sesuai dengan Akreditasi Rumah Sakit Versi 2012. JIKMU, Vol. 5, No. 2. 